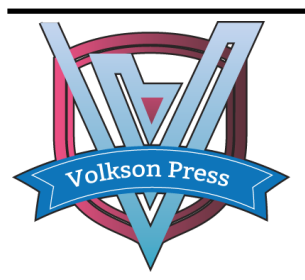

Contents List available at VOLKSON PRESS

Education, Culture and Social Development (ECSD)

DOI : http://doi.org/10.26480/icecsd.01.2018.30.27

Journal Homepage: : https://topicsonsocialdevelop.com/

\title{
RESEARCH AND PRACTICE ON THE CONSTRUCTION OF VIRTUAL SIMULATION EXPERIMENTAL TEACHING CENTER FOR MECHANICAL AND ELECTRICAL ENGINEERING IN LOCAL COLLEGES AND UNIVERSITIES
}

\author{
Sun Xuan, Zhang Lieping, Zhong Zhixian, Li Haixia \\ College of Mechanical and Control Engineering, Guilin University of Technology, Guilin, 541004, China. \\ *Corresponding Author Email: Sunxuan@glut.edu.cn
}

This is an open access article distributed under the Creative Commons Attribution License, which permits unrestricted use, distribution, and reproduction in any medium, provided the original work is properly cited

\section{ARTICLE DETAILS}

\section{Article History:}

Received 12 November 2017 Accepted 12 December 2017 Available online 1 January 2018

\section{ABSTRACT}

Aimed at lagging laboratory construction of local colleges and universities, the use of construction of virtual simulation experimental teaching center, enhance the level of experimental equipment and the level of teaching. This paper describes the idea and the thought of the center construction, based on construction and practice of virtual simulation experimental teaching center of mechanical and electrical engineering in Guilin University of Technology, focusing on resource construction, virtual simulation experimental teaching management and sharing the platform construction, experimental teaching and management team construction and management system and so on, It is expected to provide reference for the construction of the related virtual simulation experimental teaching center.

\section{KEYWORDS}

Virtual simulation, experimental teaching center, mechanical and electrical engineering, construction of laboratory.

\section{INTRODUCTION}

For the purpose to Implement the spirit of (File number 2012-4), according to document 2012-4 "Several opinions of the Ministry of Education on comprehensively improving the quality of higher education", according to the document "Ten Years Development Plan for Education Informationization (2011-2020)", in 2013, Higher Education Department of Ministry of Education issued document 2013-94 "Announcement on Developing the National Virtual Simulation Experimental Teaching Center". In August 2014 and June 2015, the general office of the Ministry of Education issued document 2014-30 and 2015-24, "Announcement on the Continuing Development of the National Virtual Simulation Experimental Teaching Center".

In August 2017, the general office of the Ministry of Education issued the document 2017-47 "Announcement on the Construction of a Model Virtual Simulation Experiment Teaching Project for 2017-2020", launching teaching project authentication work 2017 for virtual simulation experiments. By the beginning of 2016, a total of 300 national virtual simulation experimental teaching centers have been built $[1,2]$. These centers are mainly concentrated in unveristies directly under the Ministry of Education and in economically developed areas [3]. Local universities and colleges, especially universities and colleges in the west, should build and develop their own virtual simulation experiment teaching in the tide of the virtual simulation experiment teaching center advocated by the country, improve the quality of practical teaching, and train high-quality talents for local economic construction and social needs.

The virtual simulation experimental teaching center focuses on the construction of resources, platforms, teams and systems, and the formation of an organic whole that sustains service experimental teaching and guarantees the open and sharing of high-quality experimental teaching resources [4]. Our college has made certain progresses and gained some successful experiences in mechanical and electrical engineering experimental teaching, but there are still defects in virtual simulation experimental teaching. This article summarizes the construction concepts, construction ideas, and construction contents of the construction of virtual simulation experimental teaching center for mechanical and electrical engineering of Guilin University of Technology.

\section{CONSTRUCTION CONCEPTS}

The General Office of the Ministry of Education propound explicitly in the document that "the construction of a virtual simulation experimental teaching center should give full expressions the principle of combination of virtualness and reality, mutual complementation, and virtualness rather than reality if possible, realizing teaching functions that are not available or difficult to complete in real experiments, "Virtual simulation" The construction of experimental teaching center adheres to the guiding ideology of "scientific planning, sharing of resources, highlighting key points, improving efficiency, and sustainable development", with the aim of improving the innovation spirit and practical ability of college students, and focusing on the sharing of high-quality experimental teaching resources. Informatization experimental teaching resources are the focus, and the continuous advancement of experimental teaching information construction and experimental teaching reform and development in colleges and universities" [5,6].

The virtual simulation experimental teaching center for mechanical and electrical engineering of Guilin University of Technology is based on virtual simulation laboratory of mechanical engineering major, as well as virtual simulation laboratory, engineering training center and electrical and electronic virtual simulation laboratory of automation major. The concept of the establishment of an electromechanical engineering virtual simulation experimental teaching center in our college is based on the principle of combination of virtualness and reality virtualness rather than reality if possible, on the basis of virtual simulation laboratory and entity laboratory, merging the three specialties of mechanical engineering, mechatronic engineering and automation as well as the non-machine major in machining and non-electrical major in electrical and electronic technology together, through the crossing and Integration of mechanical and electrical discipline knowledge systems, the integration of mechanical and electrical technology and modern information technology, the 
integration of entity experiments and virtual simulation experiments, the integration of theoretical teaching and practical teaching, realizing the organical integration of teaching and experimentation of mechanical and electrical engineering, and enhancement of scientific thinking and exploration spirit, practical ability and innovation ability of students.

\section{CONSTRUCTION IDEAS}

The virtual simulation experimental teaching center for mechanical and electrical engineering in our college is mainly to serve practical courses of the three undergraduate specialties of the college, the non-engineering undergraduate major in mechanical processing and non-electric undergraduate major in electrical and electronic technology. During the course of being constructed, after a discussion in the college faculty meeting, the function and role of virtual simulation experimental teaching center for mechanical and electrical engineering in the college should also serve the experimental practice of graduate students and the scientific research of teachers, establishing the virtual simulation experimental teaching center for mechanical and electrical engineering as a comprehensive virtual simulation center for mechanical and electrical engineering.

The architecture diagram of the virtual simulation experimental teaching center is shown in Figure 1. The virtual simulation experimental teaching center for mechanical and electrical engineering includes three professional virtual simulation platform and two basic training engineering modules. It integrates the faculty and teaching resources of the whole college and uses an open virtual simulation experimental website into a platform to achieve resource sharing.

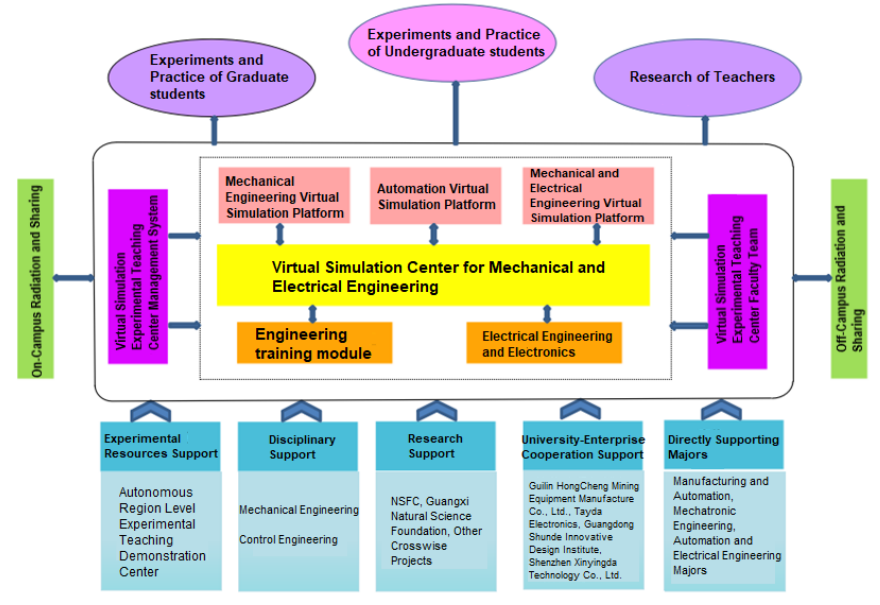

Figure 1: Architecture diagram of virtual simulation teaching experimental center

Virtual simulation experimental teaching experiment center is based on entity laboratory, aiming at high cost, high consumption, high-risk or extreme environment, unreachable or irreversible operation, and virtual experiment projects developed by large-scale, valuable equipments and devices, to provide reliable, safe and economical experiment projects that allow students do experiments in virtual experiments and achieve teaching functions that not available or difficult to complete in real experiments, and achieve the teaching effect required by the syllabus [7]. In the construction of a specific experimental teaching system, a "three levels, four modules, and five integrations" virtual experimental teaching system is proposed, specifically aiming at capacity improvement, based on professional modules, and with the purpose of application, and achieve the integration of knowledge of mechanical and electrical specialties. The virtual experimental teaching system is shown in Figure 2.

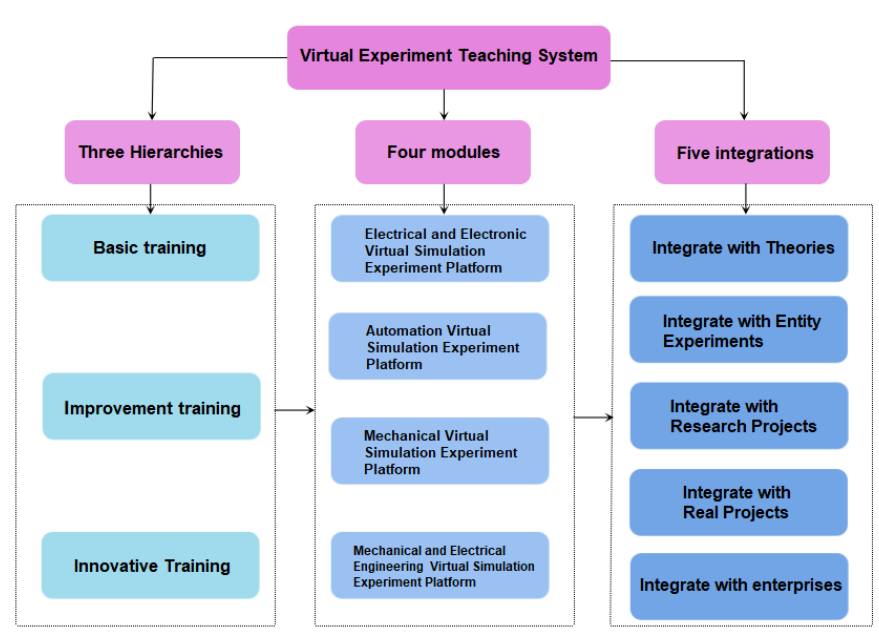

Figure 2: Virtual experiment teaching system

\section{CONSTRUCTION CONTENTS}

According to the spirit of the document issued by the Ministry of Education, the construction of virtual simulation experimental teaching center mainly includes virtual simulation experiment teaching sources, virtual simulation experimental teaching management and sharing platform, virtual simulation experimental teaching and management team, virtual simulation experimental teaching center management system. The following briefly describes the construction content of the virtual simulation experimental teaching center for mechanical and electrical engineering in our college.

\subsection{The construction of virtual simulation experimental}

The first in the construction of teaching resources is to integrate current resources of laboratories, and then develop new teaching resources. Softwares used in each course are not only professional softwares, but also generally have functions of virtual simulation, such as the CNC manufacturing engineer software CAXA of the metalworking practice experiment center. The teaching softwares of the laboratory of mechanical engineering major include AutoCAD used in 2D design, Soliworks and Pro/E used in 3D design, UG and CATIA used in mold design, Anasys used in structural analysis, Adams used in mechanical dynamics, and professional course-specific simulation softwares, mechanism movement and mechanical design virtual simulation software GZC-JS, mechatronics virtual simulation software GZC-JD, hydro-pneumatic simulation teaching software, three-coordinated measuring machine simulation teaching software PC-DMIS, injection molding analysis softwares, etc.. Common simulation softwares of automation major include simulation software Protel DXP, MATLAB, LabVIEW, IRAI, as well as configuration software SIMATIC WinCC of Siemens, dedicated simulation software SMPTLab1000 of Siemens.

Each software above corresponds to one or more theoretical courses, and the experiment of each course only uses a few functions of the software to open a corresponding small simulation experiment. It does not fully utilize the performance of the software. Students only learned and understood parts of functional characteristics of the softwares, or learn a certain knowledge point through simulation experiments, and cannot systematically complete the knowledge system. Aiming at the present problems, the college provided certain fund for teachers who have requirements on educational reform for the use of construction of the simulation experiment project for the course, and built the virtual experiments of the three majors and two modules of the college as a virtual simulation experiment teaching system with vertical and horizontal combination, system perfection, and open sharing.

After more than three years of accumulation, we have achieved certain achievements in the experimental construction of automation professional Siemens dedicated simulation software SMPTLab1000 and mechanical professional software Pro/E. Students of automation major received special prizes in the national finals of Siemens Cup China Intelligent Manufacturing Challenge for two consecutive years. There 
were around 30 students of mechanical engineering each receiving a 3D design engineer certificate from the Education Management Information Center of the Ministry of Education, and won several prizes in national 3D design competitions. Figure 3 shows the simulation interface students used in the national finals of Siemens Cup China Intelligent Manufacturing Challenge 2017. Figure 4 shows its specific parameters. Figure 5 shows the works of the National 3D Innovation Design Competition.

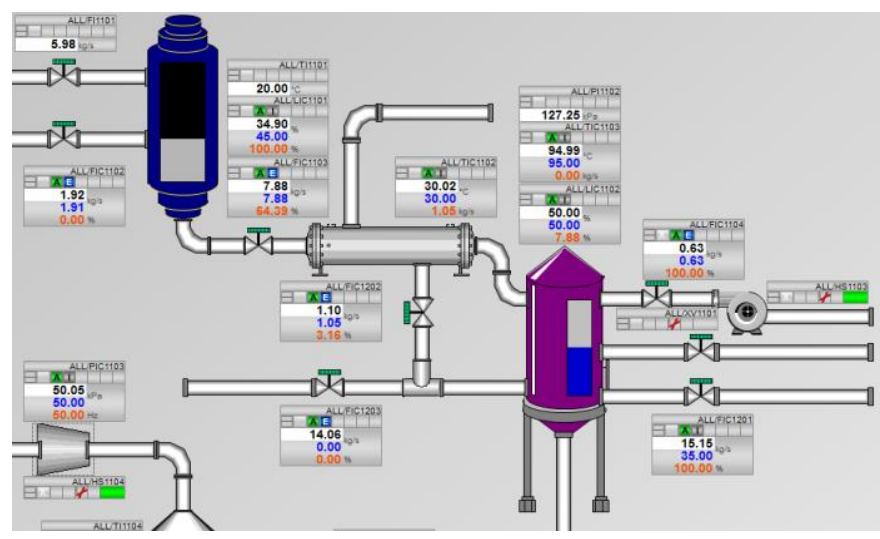

Figure 3: The Simulation Interface for the National Finals of Siemens Cup Industrial Automation Challenge 2017 (Debug)

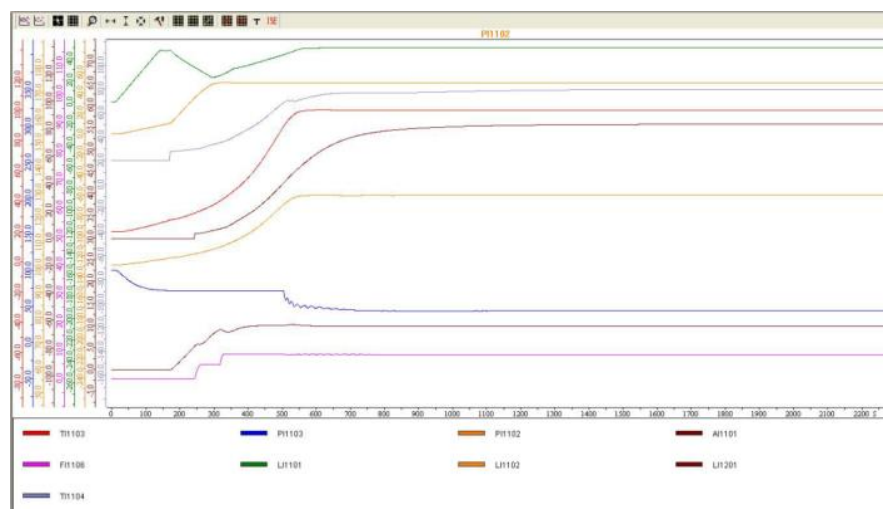

Figure 4: Simulation and debugging parameters curve for the National Finals of Siemens Cup Industrial Automation Challenge 2017

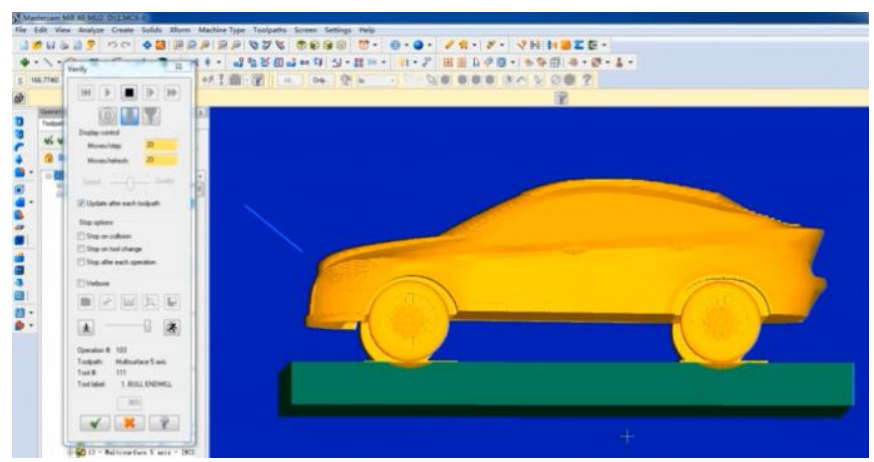

Figure 5: The works of the National 3D Innovation Design Competition

\subsection{Virtual simulation experimental teaching management and construction of sharing platform}

The open virtual simulation experiment teaching management and sharing platform was jointly built with Beijing Rainier Technology Co., Ltd. The system relies on the campus network and enhances experimental practice teaching with virtual experiment technology and network information technology.

The open virtual simulation experiment teaching management and sharing platform includes subsystems such as web portal of virtual experiment center, pre-experimental theoretical learning, experimental start-up management, typical experimental library maintenance, experimental teaching arrangement, intelligent guidance of the experimental process, automatic correction of experimental results, experimental results statistics query, digital resource management, teacher-student interaction and system management. Platform function framework diagram is shown in Figure 6.

The web portal of virtual experiment center includes center introduction, experiment teaching, experiment team, management mode, equipment and environment, teaching features and center news/announcement/notice, etc. Experimental educational management includes curriculum library, training plan, scheduling, class selection, and class review. Experimental teaching management includes physical experiment arrangement, virtual experiment arrangement, experimental correction, attendance management, performance management, and experiment report. Pre-experimental theoretical learning includes students learning experimental theory before practice through exercises, self-tests, and courseware. Intelligent guidance of the experimental process includes that students can request guidance when encounter problems during the experiments, then the system will provide guidance information. The system administrator mainly manages system user accounts and experimental student groups, provides import/export, add, delete, check, and change functions, and maintains roles and corresponding permissions for participating in experimental teaching. Management rights function.

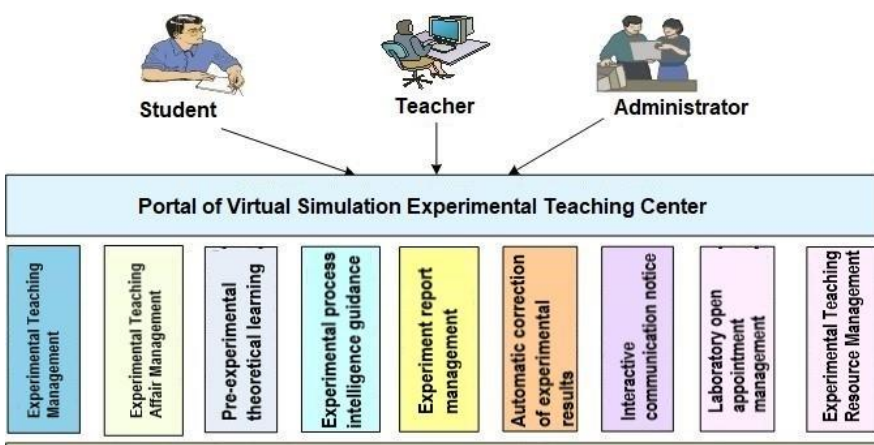

Open virtual simulation experiment teaching management and sharing platform

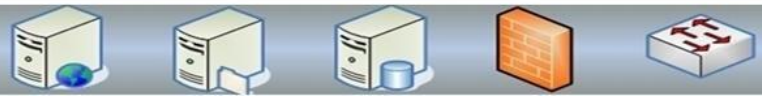

Figure 6: Functional framework diagram of open virtual simulation experiment teaching management and sharing platform

\subsection{Virtual simulation experiment teaching and management team construction}

The virtual simulation experiment teaching also follows the requirements of the teaching law, and it is regulated from the aspects of the setting, content, and discipline integration of virtual simulation experiments. First of all, requirements are set on the virtual simulation experiment setup, that is, there are physical experiment equipments to use the physical experiment equipments for experiments; for experiments without physical equipment experiments, high-pressure and high-risk experiments, and physical equipments that use precious equipments less (five-axis CNC machining centers, flexible manufacturing systems, coordinate measuring machines, etc.) actively develop virtual simulation experiments; the degree of difficulty in virtual simulation experiments also requires basic training, improved training, and progressive progression to capability training, that is, from simple to complex, from point to surface, set from the local to the global level.

The content of the virtual simulation experiment is required to reflect the integrity and systematism of the knowledge, and can fully grasp and understand the theory via virtual simulation experiment. The contents of the virtual experiment should also pay attention to the the individualized learning and the development of comprehensive ability of students.

It has also been put forward in terms of integration of disciplines. The virtual simulation experiment should not only pay attention to the experiment corresponding to the theoretical teaching of this course, but also pay attention to the internal connection between the experimental content of the entire professional, not only consider the relative independence of the experiment in the professional experimental teaching 
system, but also pay attention to each Systematic, interrelated, and interactive among disciplines.

The virtual simulation experiment teaching should cover the open experimental and practical teaching systems of the three undergraduate majors of mechanical design and manufacturing and automation, mechanical and electronic engineering, and automation, as well as the two modules of engineering training center and the electric and electronic technology. Take the modular and hierarchical experiment as the main line, and use the virtual experiment of the independent theoretical course knowledge system to connect students together. Let students learn the system's theoretical knowledge through simulation experiments in an interactive environment, thus forming and theory. The curriculum system has both an organic combination and a relatively independent teaching platform.

The teaching team of the virtual experiment teaching center consists of high-level teachers inside and outside the university, such as mechanical engineering, mechanical and electronic engineering, and automation. Teachers of different majors take the teaching modules of each experimental teaching platform as the main line, and the teaching team consists of professors, lecturers, regular teachers, experimental teachers, experimental staffs. There are 37 regular and adjunct experimental teachers, including 5 professors, 7 associate professors, 2 senior engineers (senior laboratory), 10 lecturers, 8 engineers and 1 technician. There are 12 doctors and 17 masters. The proportion of full-time experimental teaching and technical personnel with a bachelor degree or above has reached $100 \%$, and the proportion of personnel with a specific middlelevel or higher professional title is $79 \%$.

After nearly a decade of construction and development, this center has become an experimental teaching team with a reasonable structure, high level of teaching and research, and strong development strength to meet the needs of undergraduate and innovative personnel training, forming a powerful, efficient, and open experiment. The room management system has become a virtual imitation experimental teaching center with advanced equipment and first-class environmental conditions in the whole autonomous region, which provides a strong support for the cultivation of innovative talents in our university.

\subsection{Construction of management system of virtual simulation experimental teaching center}

The virtual simulation experimental teaching center implements a twoleveled management of the university and the center, and the director of the center is responsible for the management system. The school is responsible for overall planning and construction. The center is responsible for daily management and operation. College of Mechanical and Control Engineering undertakes teaching tasks. The director of the center is fully responsible for the construction and management of the experimental teaching center. The focus of the work is planning, organization, construction, and supervision and control of the center, leading members of the center to carry out scientific research, teaching and research, and education reform. The center set up 2 deputy directors who are responsible for the daily teaching and management of the center and are responsible for the director of the center.

\section{PROBLEMS AND DIFFICULTIES IN THE CONSTRUCTION OF VIRTUAL SIMULATION EXPERIMENT TEACHING CENTER}

In the process of building a virtual simulation experimental teaching center, there are two problems and difficulties encountered. One is the technical problem, mainly different software of different courses and different majors are difficult to be integrated on a platform, now this problem is handed over to Beijing Uniner Technology Company; the other is the virtual simulation of large and valuable equipment. For the development of the experiment, we contacted with Beijing Greiner Technology Corporation and was solved by a professional company. The other is the financial issue. After the mechanical and electrical engineering virtual simulation experiment teaching center was approved by the school, it allocated 500,000 funds. The college itself raised nearly half a million. Nearly one million funds can only be used to build a website. Platform, several small simulation experiments, and the development of simulation models for several large devices. The lack of funding has severely delayed the construction of a virtual simulation experiment teaching center.

\section{CONCLUSIONS}

The virtual simulation experimental teaching center is an important part of the construction of higher education informatization and the construction of experimental teaching demonstration centers. It is a product of the deep integration of disciplines and information technology. Through the construction of virtual simulation experimental teaching centers, local engineering colleges can integrate limited experimental resources, achieve resource sharing, improve the efficiency of laboratory use, and standardize the management of laboratories. Through the combination of traditional physical experiment teaching and virtual simulation experiment teaching, it is conducive to students' ability of independent innovation and practical application, and provides application-oriented and innovative talents for local economic development.

\section{ABOUT THE AUTHOR}

Sun Xuan (1970.07- ), Male, Songzi, Hubei. Doctor, Associate Professor, Associate Dean of College of Mechanical and Control Engineering, Guilin University of Technology. The main research direction is virtual instrument, detection technology and data processing.

\section{FUNDING}

This work is partially supported by Guangxi Higher Education Undergraduate Education Reform Project (No. 2016JGB236), Guangxi Higher Education Undergraduate Education Reform Project (2017JGB128), and Guilin University of Technology Graduate Student Quality Course Construction Project (105962016yzkc013).

\section{REFERENCES}

[1] Meng, Y.M. 2016. Research and Practice of Virtual Simulation Experimental Teaching System for Mechanical Engineering. Experimental Technology and Management, 33 (5), 109-112.

[2] Song, Z.H., Chen, D., Dong, X.Q. 2017. Construction Planning and Practice of Virtual Simulation Experimental Teaching Center for Mechanical and Agricultural Engineering, 34 (1), 5-9.

[3] Peng, X.J. 2016. Exploration on the Construction of Virtual Simulation Experiment Teaching Center under the New Normal of Higher Education. Experimental Technology and Management, 33 (11), 237-240.

[4] Zu, Q., Wei, Y.J. 2015. An Analysis of the Status Quo of the National Virtual Simulation Experimental Teaching Center Construction. Experimental Technology and Management, 32 (11), 156-158.

[5] Liu, Y.F., Yu, L.J. 2016. Exploration on Construction Concept and Development Mode of Virtual Simulation Experimental Teaching Center. Experimental Technology and Management, 33 (4),108-110.

[6] HED. 2014. Announcement of the General Office of the Ministry of Education on the Construction of the National Virtual Simulation Experimental Teaching Center in 2014, Higher Education Department, 30.

[7] HED. 2015. Announcement of the General Office of the Ministry of Education on the Construction of the National Virtual Simulation Experimental Teaching Center in 2015, Higher Education Department, 24. 